\title{
Subscribers' Perception of SIM Card Retrieval: Implications on Criminality and Behaviour in Calabar Municipality, Cross River State
}

\author{
Eraye C. Michael \\ Eke C. Chinwokwu \\ Silvia K. Arop \\ Department of Sociology, Federal University, Lafia, Nigeria \\ Email: chriseraye@yahoo.com
}

Doi:10.5901/mjss.2014.v5n10p620

\begin{abstract}
The study is concerned with Subscribers Identification Module (SIM) retrieval in Calabar Municipality. The general objective of the study was to examine the subscriber perception of the factors responsible for SIM card retrieval and its implication on criminality and behaviour. To achieve the general objective, the study purposively elicited data via questionnaire and in-depth interview from 387 MTN, Globacom, Airtel, and Etiselat network subscribers and staff of telecom companies. Descriptive statistics was employed to analyze quantitative data generated via questionnaire and qualitative data was subjected to content analysis. Finding revealed that loss of phone with the SIMs, damage to SIMs, stolen phones with the SIMs and faulty SIMs were factors associated with SIM card retrieval. Findings further revealed that subscribers prefer to retrieve their previous SIMS than buying new ones; so as to reconnect with their friends and loved ones and to prevent criminals who have stolen or snatched their phones from using the lines to commit crime and implicate them. It was also discovered that Female more than male subscribers are more likely to have their SIMs retrieved because they are more victims of stolen Phone/SIM and damaged SIMs. It was established that the prevalence of SIM retrieval depicts an upsurge in crime such as theft and the snatching of valuables, insincerity in our society and carefree attitude among subscribers. We recommended among others, that the government should address the problem of unemployment which is fingered as the major cause of property crime in Nigeria and that there is need for value reorientation. We also propose that network providers should come up with packages that will make SIM retrieval less cumbersome and provision of more durable SIM cards for subscribers.
\end{abstract}

Keywords: Network, Retrieval, Subscriber Identification Module, theft, crime and Vauables.

\section{Introduction}

This study is on the prevalence of Subscriber Identification Module (SIM) cards retrieval in Calabar Municipality. The Subscriber Identification Module is a mandatory security module located in the mobile telephone of a GSM system, as an exchangeable component (Rischard, 1996). The SIM is an entity that contains the identity of the subscriber and primarily to secure the authenticity of the mobile station with respect to the network. SIM cards allow programme execution to be protected against manipulation and makes it possible to store data such as dialing numbers, short message service (SMS) and personal configuration settings for the mobile telephone. It is a mandatory component of a mobile phone, without it, calls cannot be made.

Aderamola (2013) opined that Subscriber Identification Module (SIM) is an integrated circuit that securely stores the international mobile subscriber identity and related key, used to identify and authenticate subscribers on mobile telephony devices such as mobile phone. SIM card contains its unique serial number (SN), international mobile subscriber authentification (IMSA), temporary information related to the local networks and a list of the services that a user has access to. When inserted into mobile phone, calls can be made, received and small message service (SMS) can be received and sent to others (Ajumola, 2010). SIM is a symbol of identity; with it a subscriber can identify a caller and the person who has sent a message. With SIM, vital information are kept and protected. Due to the importance of SIM to the network providers and subscribers, important provision has been made for retrieval should anything happen to it (Adaramola, 2013). All network providers have developed a welcome back package for reactivating SIM cards of prepaid customers whose SIM may have been stolen or damaged. Nurudeen (2013) observed that many subscribers at one point had SIM card retrieved. According to him 6 in every 10 subscribers to various networks have had their SIM cards retrieved. Similarly, Nwadike (2010) observed that number of subscribers who have reactivated their SIM cards in 
Nigeria is high. For him, about 38\%, 29\% and 24\% of subscribers to MTN, Airtel and Globacom between 2006 and 2008 had subscribed to the welcome back package of the various network providers. This implies that many of the subscribers to various networks are currently using retrieved SIM. The various stakeholders in the telecom sector such as all the private and public telecommunication operators, consumer group, security agencies, government agencies and media houses are worried by the rate at which subscriber demand for SIM retrieval.

There is an increase in SIM retrieval in Nigeria. Retrieval requires subscribers leaving the comfort of their homes, offices and other places of business to the office of network providers (Nwadike,2010). Even with the introduction of online SIM cards retrieval, subscribers spend several hours on the internet trying to retrieve their lines because of poor internet connectivity. The difficulty involved in SIM reactivation makes the subscriber worried, especially as the subscriber is socially disconnected from friends, associates and loved ones. While in the process of retrieving their previous lines, parents, friends, children and other relatives become worried as the subscriber cannot be reached . This is more worrisome considering the security challenges in society. The social disconnections loss of man-hours and the resources involved in the retrieval of SIM cards make subscribers worried when their GSM lines are inactive. On most occasions, subscribers spend several hours in MTN, Globacom, Airtel offices without achieving their aim, and may have to return the next day for the same purpose. This breeds frustration, anxiety and waste of resources.

Previous study by Longe and Oguntuyi (2012) focused on the pains and gains associated with Global system of mobile telecommunication. Other studies by Adeyinka, Ajiboye, Emmanuel, and Wojuade (2007); Ndukwe(2004) and Bakare and Gold (2011) dwelled on the impact of GSM on Nigeria's Rural Economy. by Hitimans (2011), Bogere (2011) concentrated more on the contributions of GSM to societal development, the evolution of SIM cards and SIM card registration as a tool in curbing criminality. No information has been provided on SIM cards retrieval and associated problems among subscribers in Calabar Municipality. Therefore, an empirical understanding of SIM card retrieval by subscribers is required so that appropriate solution could be advanced. Thus, the pertinent questions are: What happened to the previous SIM card before the subscriber resolve to retrieve it? Why do the subscribers prefer retrieving their previous lines than buying new one? What gender is more likely to have their SIM retrieved? What are the implications of persistent SIM card retrieval on crime and behaviour?

\section{Literature Review}

The subscriber identification module is a mandatory security module located in the mobile telephone of a GSM system, as an exchangeable component (Rischard, 1996). The SIM is an entity that contains the identity of the subscriber and primarily to secure the authenticity of the mobile station with respect to the network. SIM cards allow programme execution to be protected against manipulation and makes it possible to store data such as dialed numbers, short message service (SMS) and personal configuration settings for the mobile telephone. It is a mandatory component of a mobile phone, without it, calls cannot be made. The revolution in Information and Communication Technology (ICT), through the liberalization and deregulation of the telecom sector has provided opportunities for many Nigerians to own and operate a mobile phone.

Telecommunication is acknowledged as one of the most important infrastructures essential for the socio-economic well- being of any nation (Longe \& Oguntuyi, 2012). The revolution in the telecommunication sector of Nigeria's economy has impacted enormously on the masses, especially since the introduction of Global System of Mobile telecommunication in the industry. There is no doubt that increase in the use of mobile communication globally has transformed lives in Africa, where fixed telecommunication was severely limited and in many cases in far rural communities. Mobile communication has proved to be convenient and effective technology for farmers, small-scale traders, government workers, and providers of essential services across the continent. The emergence of Global System of Mobile Telecommunication (GSM) has put into effective check the monopoly of the Nigerian Telecommunication Limited on telephony ( Agba, Ikoh, Ushie \& Bassey, 2010) This has created opportunities for many people who before had no mobile phones to acquire and use one, to ease communication problems, and discourage the monopoly enjoyed by Nigeria Telecommunication limited. This was made possible by the liberalization of the Nigerian Telecom sector over a decade ago by Nigerian Government. Government deregulation and liberalization policies in the telecommunication industry provided ample opportunities for investors to come into the telecom industry. Many investors keyed into the liberalization policy and became network providers (NP). MTN, Airtel, Globacom, Zoom, Starcom, Multilinks and Etisalat have been major players in the industry, providing network coverage for many subscribers. With the proliferation of network providers, the number of subscribers increased with MTN leading with over 45 million subscribers and more subscribers being added daily (Rischard, 1996, NCC,2012).

Acknowledging the exponential rise in the number of subscribers to various networks, Ndukwe (2005) reported that 
between 1999 and 2004, the number of connection on fixed lines increased from 450,000 to 1,120,000. A Similar report by Nigerian Communications Commission (NCC) as shown on table 1 revealed that subscribers to the aforementioned networks have witnessed a progressive increase over the years.

Table1: Number of Subscribers from $2000-2011$

\begin{tabular}{|c|c|c|}
\hline Year & Total Subscribers & Teledensity \\
\hline 2011 & $95,886,714$ & $68.49 \%$ \\
\hline 2010 & $88,348,026$ & $63.11 \%$ \\
\hline 2009 & $74,518,264$ & $53.23 \%$ \\
\hline 2008 & $64,296,117$ & $45.93 \%$ \\
\hline 2007 & $41,975,275$ & $29.98 \%$ \\
\hline 2006 & $33,036,761$ & $24.18 \%$ \\
\hline 2005 & $19,519,154$ & $16.27 \%$ \\
\hline 2004 & $10,201,728$ & $8.50 \%$ \\
\hline 2003 & $4,021,945$ & $3.35 \%$ \\
\hline 2002 & $2,271,050$ & $1.89 \%$ \\
\hline 2001 & 866,782 & $0.73 \%$ \\
\hline 2000 & 588,374 & $0.50 \%$ \\
\hline
\end{tabular}

Source: Nigeria Communication Commission, 2012

As at February 2012, statistics showed that, there were 116,439,548 subscribers in Nigeria (NCC, 2012). The astronomical increase in the number of subscribers implies that more and more communities are being covered with networks, as mobile phones usage has become common in Nigeria (Nurudeem,2013). As many become mobile phone users, the challenges of maintaining handsets became pronounced. Apart from the mobile phone developing faults, some who had issues with their phone lines had to resort to retrieving them. Ordinarily no subscriber will retrieve his SIM, if it is functioning effectively. Nnaemeka (2008) observed that a SIM is retrieved if the previous one is damaged or has developed fault. Retrieved SIM helps the subscriber to retain their mobile number so that other callers can reach them. Nwadike (2010) corroborated the view of Nnaemeka that one of the reasons subscribers opt for SIM retrieval is due to damage to the previous one. SIMs can be damaged by the subscribers or their peers. Richardson (2011) maintained that subscribers retrieve their lines when the previous one is stolen. Thus, Michael (2010) observed that commercial motorcycle operators who indulge in criminal activities often target mobile phone and other valuables. Many mobile phones containing the SIM have been snatched from their owners by criminals. Akpan (2010) reported that many commuters had been victims of criminals who snatched their mobile phones and other valuables. In order to maintain their contacts, victims upon getting another phone go for SIM retrieval. Nwadike (2010) asserted that $90 \%$ of subscribers intending to retrieve or had retrieved their line had it snatched with their hand sets. According to Olubamidele (2012) the cheapness of mobile phones has not in any way stopped criminals from snatching handset. Once the mobile phone is snatched or stolen with the SIM, the only option is to retrieve the line, should the subscriber intend to retain his contact.

Kenneth (2007) observed that most mobile phones are not stolen, but the subscriber may lose it. According to him, some mobile phones containing the SIM are forgotten by the subscribers. Nnaemeka (2008) acknowledged the level of moral decay and insincerity in Nigeria. According to him, it is quite difficult for people to pick up anything belonging to another person and return same to the rightful owners. Subscribers have had their mobile phones, handbags and other valuables forgotten in public places and commercial vehicles without recovering them because people who pick them up never returned them to the owners or took them to the nearest police station. Also Akpan (2010) opined that it has become a common practice in Nigeria for people to pick up valuables belonging to another person without returning them to the rightful owners even when the owner is known. In another opinion, some SIM cards are not stolen; rather they may have developed faults. A SIM card produced with inferior materials is most likely to develop fault than that which is produced with durable materials faster.

No general consensus exists regarding the relationship between gender and subscribers identification module retrieval. Nwadike (2010) observed that both male and female have been victims of stolen, lost and damaged SIM cards. Adaramola (2013) could not see gender difference in SIM retrieval. According to him, male as well as female have had their lines retrieved. Amadi (2010) was of the view that more females than male were victims of motorcyclist criminals who always target valuables such as hand bags, mobile phones and other valuables. Smith (2009) maintained that more 
female than male had their valuables including handsets snatched because they use expensive camera phones than their male counterparts.

\section{Theoretical Framework}

This study is grounded in the Rational Choice Theory and Actor-Network Theory.

The focus of rational choice theory is on actors (Ritzer, 2008). The actors have goals towards which their actions are aimed. Actors have preferences which may be arranged on a hierarchy. The action of every actor is consistent with the attainment of objectives. The theory takes cognizance of a major constraint on action. The scarcity of resources and the opportunity cost. In pursuing a given end, actors must keep an eye on the costs of forgoing their next most attractive action. Actors are seen as trying to maximize their benefits and that goal may involve accessing the relationship between the chances of achieving a primary end and what that achievement does for the chances of attaining the second most valuable objective. The theory assumes that an actor is a rational being who make choices and take action based by weighing the costs and benefits of their action or decision. From this theory, subscribers are rational beings who will always decide to subscribe to welcome back package if the benefits of retrieving their previous lines outweighs the cost of buying a new line. The benefits are of their action is more social than economical. The social benefits involve retrieving their previous lines so as to reconnect with their loved ones, prevent criminals from using their lost lines for crime thereby implicating them.

The Actor-Network Theory (ANT) assumes that there exists a correlation or interaction between technology and the users (Latour, 1992). Both technology and members of the society are interrelated actors involve in shaping the society. Technological tools are invented or created by humans, the use of these tools shape their actions enormously. The advancement in Information and Communication Technology (ICT) especially the use of mobile phones has shaped the behaviour of members of the society. The use of mobile handsets had negatively shaped the behaviour of society. Many users are now addicted to mobile handsets such that it has affected their once cherished relationships and also result in the destruction of their phones and SMS by loved ones. From ANT, the existence of mobile phones has influence criminality in the society. While mobile phones are targeted by criminals, there are also used for criminal activities.

\section{Methodology}

Methodology is basically the bedrock of any scientific enquiry. It specifies how data will be collected and analyzed.

\subsection{Research Design}

The study adopted descriptive survey research design. This is a method of gathering information about a population by selecting samples. It is the best method for researchers who are interested in collecting first hand information from the population.

\subsection{Study Area}

The study was conducted in Calabar Municipality, Cross River State. It is one of the urbanized Local Government Areas in South-South Geopolitical zones (SSGZ) and was part of the first administrative headquarters of the Southern protectorate of Nigeria. Calabar Municipality is bounded in the North by Odukpani Local Government Area, in the South by Calabar South Local Government Area. It has a total population of 179,392 (National Bureau of Statistics, 2006). The municipality has witnessed rapid influx of people into the town, and socio-economic transformation occasioned by continued urbanization as well as modernization and development. It is a tourism nerve of the Nation. It is a tourist destination with many commercial enterprises. The establishment of the Export Free Zone in Calabar City has tended to pull migrants and business people expecting new socio-economic opportunities into the city (Michael ,Ojedukun \& Chinwokwu, 2013). Consequently, the city has witnessed an increased in population with many who have subscribed to mobile networks.

\subsection{Sample Size Determination.}

The Yamane's (1967) sample size determination technique was employed to determine the sample for the study. It states that for a population greater than 100,000 , a sample size of 400 be selected at $\pm 5 \%$ level of precision. The population of 
Calabar Municipality according to 2006 census was put at 179,392. The respondents were selected from 5 electoral wards within Calabar Municipality. In addition two (2) members of staff each from the various mobile network providers (MTN, Globacom, Airtel and Etisalat) were also involved in the study. This yielded a total sample size of 408 respondents.

\subsection{Sampling Techniques and Procedures}

A combination of sampling techniques was employed to select respondents. Five (5) political wards were selected from the (10) ten political wards in Calabar Municipality, using the simple random sampling method. From the five (5) wards, five (5) enumeration areas (EAs) each were randomly selected, making a total of twenty five (25) enumeration areas. Out of the enumeration areas, sixteen (16) respondents each were selected purposively, making a total of 400 respondents.

\subsection{Instrument of data collection}

To generate quantitative data, set of well structured copies of questionnaire were distributed to the respondents, covering their socio-demographic characteristics and the research objectives. The items were designed in both open and closedended format. The instrument was administered on 400 respondents by the researchers. For qualitative data, indepth interviews were held with eight members of staff of mobile network providers located in Calabar Municipality. Two (2) members of staff (customers Service) each from MTN, Globacom, Airtel and Etisalat were purposively selected and interviewed. The result from the indepth interviews was integrated with that of the quantitative study to give the study a valid outcome.

\subsection{Data Analysis}

At the analysis stage, the descriptive statistics involving frequency distributions and simple percentages were employed. Data generated on the Socio-demographic characteristics of the respondents were described using tables and simple percentages. Similarly, simple percentage was employed to present and describe data generated to answer research questions. Qualitative data was subjected to content analysis.

\section{Results and Discussion}

\subsection{Socio-Demographic Characteristics of Respondents}

As shown on table 2, more than half of the respondents were $(N=183,47.3 \%)$ female as against $(N=204,52.7 \%)$ male respondents. The age of the participant weighs heavily in favour of youths. About 76.5 percent of the respondents were in the age bracket of $15-45,13.9 \%$ of the study participants were between age 46 and 55 and participants in the age category of 56 years and above accounted for $9.6 \%$. The implication is that more of the participants were still in their youthful age and these age cohorts are more intoned with the use of modern technology such as mobile phones.

Table 2: Socio- demographic Characteristics of Respondent

\begin{tabular}{|l|c|c|}
\hline Variables & Frequency & Percentage \\
\hline Gender & & \\
\cline { 1 - 1 } Male & 183 & 47.3 \\
Female & 204 & 52.7 \\
Total & 387 & 100 \\
\hline Age & Frequency & Percentage \\
\cline { 1 - 1 } $15-25$ & 101 & 26.1 \\
\cline { 1 - 1 } $26-35$ & 97 & 25.1 \\
\cline { 1 - 1 } $36-45$ & 98 & 25.3 \\
\cline { 1 - 1 } $46-55$ & 54 & 13.9 \\
\cline { 1 - 1 } $56+$ & 37 & 9.6 \\
\cline { 1 - 1 } Total & 387 & 100 \\
\cline { 1 - 1 } Marital Status & Frequency & Percentage \\
\cline { 1 - 1 } Married & 156 & 40.3 \\
\cline { 1 - 1 } Single & 196 & 50.6 \\
\cline { 1 - 1 } Separated & 19 & 4.9 \\
\cline { 1 - 1 } & \multicolumn{2}{|c}{} \\
\multicolumn{2}{|c|}{624} &
\end{tabular}




\begin{tabular}{|l|c|c|}
\hline Divorce & 16 & 4.1 \\
\cline { 1 - 1 } Total & 387 & 100 \\
\cline { 1 - 1 } Education & Frequency & Percentage \\
\cline { 1 - 1 } No Formal Education & 29 & 7.5 \\
\cline { 1 - 1 } Primary & 81 & 20.9 \\
\cline { 1 - 1 } Secondary & 154 & 39.8 \\
\cline { 1 - 1 } Tertiary & 123 & 31.8 \\
\cline { 1 - 1 } Total & 387 & 100 \\
\hline Occupation & Frequency & Percentage \\
\cline { 1 - 1 } Civil Servant & 84 & 21.6 \\
\cline { 1 - 1 } Student & 117 & 30.2 \\
\cline { 1 - 1 } Applicants & 78 & 20.5 \\
\cline { 1 - 1 } Self-Employed & 52 & 13.3 \\
\cline { 1 - 1 } Others & 56 & 14.4 \\
\cline { 1 - 1 } Total & 387 & 100 \\
\hline Religion & Frequency & Percentage \\
\cline { 1 - 1 } Christianity & 271 & 70.0 \\
\cline { 1 - 1 } Islam & 82 & 21.2 \\
\cline { 1 - 1 } Others & 34 & 8.8 \\
\cline { 1 - 1 } Total & 387 & 100 \\
\hline
\end{tabular}

Source: Field Survey,2012

Table 2 further revealed that greater 50.6 percentages of the respondents were still single, about $40.3 \%$ had immediate family responsibility as they were married and 9.0 percent of the participants had either separated or divorced from their previous relationships. On educational qualification, 39.8\% had secondary education certificates, about 32 percent had tertiary education certificate while only $20.9 \%$ had primary education. This implies that greater percentages of the respondent had formal education and are capable of giving better information on subscriber's identification module retrieval. The table also shows that about $30.2 \%$ of the study participants were students, $21.6 \%$ are engaged in civil service jobs, 20.5 percent are applicants, $13.3 \%$ are self-employed while $14.4 \%$ accounted for participants with other occupational background such as tailoring, barbers, driver, and automobile mechanics. Finally, about $70.0 \%$ of the respondents were Christians, 21.2 percent were Muslims, while only $8.8 \%$ had other religious affiliation such as Eckankar and African Traditional Religion.

\subsection{Factors Responsible for Retrieval of Subscribers Identification Module (SIM)}

Respondents' perceptions on factors responsible for the retrieval of SIM card indicate that the many of the female respondents (31.9\%) claimed that subscribers go for SIM retrieval when their previous lines are stolen with the phone, while $20.6 \%$ indicated that subscribers opt for SIM retrieval when they lose their lines with their phones. Only a very few respondents (11.3\%) and (11.8\%) agreed that subscribers who go for SIM retrieval, lose it or the SIMs were stolen without the phones. About $24.4 \%$ of the respondents perceived that subscribers opt for SIM retrieval when their lines are either damaged by their friends and loved ones or developed fault. A similar response was given by male participants, where greater (28.4\%) of them subscribed to the view that people go for SIM retrieval when their SIM cards are stolen with the mobile phone, while $18.6 \%$ of the study participants claimed that lines are retrieved when the subscriber lose, it with the mobile phone. About $26.2 \%$ of the respondents maintained those subscribers opt for lines retrieval when they either lose only the SIM card or it was stolen without the phone.

Table 3: Gender/Factors in the Retrieval of Subscribers Identification Module

\begin{tabular}{|c|c|c|c|c|c|c|c|}
\hline Gender & $\begin{array}{c}\text { LoSs of SIM with } \\
\text { phone }\end{array}$ & $\begin{array}{c}\text { LoSs of SIM } \\
\text { only }\end{array}$ & $\begin{array}{c}\text { SIM stolen with } \\
\text { phone }\end{array}$ & $\begin{array}{c}\text { SIM stolen without } \\
\text { phone }\end{array}$ & $\begin{array}{c}\text { SIM } \\
\text { damaged }\end{array}$ & $\begin{array}{c}\text { SIM developed } \\
\text { fault }\end{array}$ & Total \\
\hline Male & 34 & 26 & 52 & 22 & 29 & 20 & 183 \\
& $18.6 \%$ & $14.2 \%$ & $28.4 \%$ & $12.0 \%$ & $15.8 \%$ & $10.9 \%$ & 100 \\
\hline Female & 42 & 23 & 65 & 24 & 28 & 22 & 204 \\
\hline \multirow{2}{*}{ Total } & $20.6 \%$ & $11.3 \%$ & $31.9 \%$ & $11.8 \%$ & $13.7 \%$ & $10.7 \%$ & 100 \\
\hline
\end{tabular}

Source: Fieldwork, 2013 
The table further depicts that $(15.8 \%)$ of the respondents perceived that subscribers go for line retrieval when their previous SIMs are damaged by self or someone, while 10.9 percentage of the respondents maintained that SIM cards are retrieved when the previous one becomes faulty because of the inferior materials used in its production. The quantitative data presented in table 3 was buttressed by qualitative data.

One of the interviewee MTN maintained that:

SIM retrieval is part of the services we render to our customers. Customers retrieve SIM when the previous one is bad or the phone is stolen with the SIM. In fact stolen phone is the commonest reason customers come for SIM Retrieval.

This respondent revealed that customers subscribed to welcome back package when mobile phones are stolen with SIM or the SIM becomes bad. The common reason for SIM retrieval is stolen phones with the SIM.

Another staff from Airtel posited that:

A customer can come for SIM retrieval when his or her phone is stolen and cannot get back the SIM. Although some customers' will tell you my SIM is damaged, only few customers will give this reason. Majority of the subscribers will tell you either their phones were stolen, or $i$ forgot it somewhere and could not get it.

This respondent share the same view with the former that SIMs are retrieved when previous ones are either stolen or forgotten by the subscriber.

This interviewee from Globacom reports that:

Customers who come for SIM retrieval do so when their SIMs are stolen or developed fault. These are the common reasons for SIM retrieval.

This respondent has similar view with others on the reason for SIM retrieval.

Another staff has this to say:

The number of customers here for welcome back increases daily. Reason for this is that many phones are stolen or forgotten somewhere. Only a very customers will lose their lines and will not do welcome back.

This staff maintains the number of customers subscribing to welcome back keeps increasing reason being that customers' phones are stolen or forgotten.

The statistical analysis and the responses generated from the in-depth interwiew showed that respondents have various reasons for SIM retrieval. The findings are in line with the observation Michael, Ojedekun and Chiwonkwu (2013) that many people in the urban centres have been victims of commercial motorcycle criminals who snatch valuables including mobile phone from them. According to Michael (2010) some of the subscribers who have their lines retrieved must have been victims of stolen phones. Smith (2009) observed that the current trend among robbers is to collect from their victims among other things mobile phones. Nwadike (2010) asserted that many lines are produced with inferior materials, thus can develop fault easily which may compel the subscriber to go for welcome back package made available by network providers. The finding further buttressed the observation of Smith (2009) that lines are damaged by boyfriends, fiancés and husbands when they consider that their partners were using it to cheat on them.

\subsection{Reasons for Preference for SIM Card Retrieval}

The respondents had different perceptions on why subscribers prefer retrieving their previous SIM cards than buying a new line which is relatively cheaper. The pie chart showed that greater $(46.6 \%)$ of the respondents perceived that subscribers prefer retrieving their previous lines to prevent criminals from using their lines to commit crime thereby implicating them. This finding is in line with the observation of Hitimana (2010) that GSMs have become tools with which people use to commit crime. Criminals use stolen mobile phones to commit crimes thereby implicating the rightful owner of the line. 


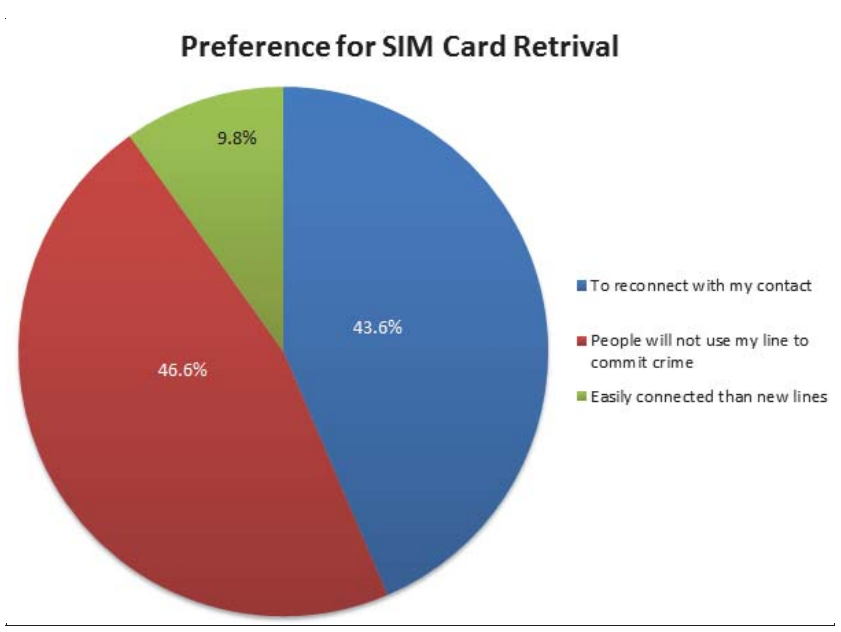

Similarly, $43 \%$ of the respondents had preference for their previous SIM cards and opted for its retrieval for the purpose of maintaining or retaining their contacts with friends, relatives and colleagues. This finding is in line with the perception of Akpan (2010) that subscribers are eager to maintain contact with their loved ones. Subscribers are anxious to retrieve their SIMs so as to reconnect with their friends and relatives.

\subsection{Gender and SIM Retrieved.}

The respondents perceived that both males and females can have their SIM retrieved. The table indicates that greater $52.4 \%$ of the respondent perceived that more females than their male counterparts are most likely to have their SIM cards retrieved.

Table 4: Victims of SIM Retrieval

\begin{tabular}{|l|c|c|}
\hline Question & Frequency & Percentage \\
\hline $\begin{array}{l}\text { Between male and female subscribers to various networks, who do you think are most } \\
\text { likely to retrieve their SIM cards? }\end{array}$ & & \\
\hline Male & 184 & 47.5 \\
\hline Female & 203 & 52.4 \\
\hline Total & 387 & 100 \\
\hline Reasons female subscribers are more likely to have their SIM card retrieved. & & \\
\hline${ }^{*}$ Lost more phones/SIM than males & 57 & 28.1 \\
${ }^{*}$ More Victims of stolen/snatched phones/SIM & 79 & 38.9 \\
*Can have their SIM damaged easily & 67 & 33.0 \\
Total & 203 & 100 \\
\hline
\end{tabular}

Source: Fieldwork, 2013

The study further revealed that females are more likely to have their lines retrieved because they are most likely to be victims of stolen phone/SIM than their male counterparts. This is indicated by $38.9 \%$. About $33.0 \%$ of the respondents perceived that females have most SIM retrieved because they can have their SIM cards damaged easily by their husbands, boyfriends and Fiancé, while, only $28.1 \%$ of the respondents claim that more females can have their lines retrieved because they loss more phones/lines than male. This finding aligns with the position of Ukwayi, Agba \& Michael (2013) that females are common victims of property crime because of their physical weaknesses. Criminals on motorbikes often target females because they are always in possession of expensive phones, fearful and are physically weaker than males. This finding also buttresses the perception of Akpan (2010) than most victims of stolen and damaged phones/ SIM cards are females. Phone and SIM can be damaged by their husbands, boyfriends or fiancée.

\subsection{Implications of SIM Retrieval on Crime and Behaviour.}

The study established that SIM cards retrieval have implication on crime against property and behaviour. Majority $(\mathrm{N}=$ 83, 59.3\%) of the female participants revealed that the upsurge in SIM card retrieval depicts that there is an increased in 
the theft of valuables and ( $N=57,40.7 \%)$ of their male counterparts perceived that there is an increase in the theft of valuables such as hand bags and purses containing GSM handset with their SIMs as shown by increase in the number of subscribers opting for SIM card retrieval. Table 5 further showed that majority $(\mathrm{N}=53,52.4 \%)$ of the male participants in the study claimed that SIM retrieval implies an increase in the snatching of mobile phones as against their female counterparts which accounted for just about ( $N=48,47.5 \%)$

Table 5: Implication of SIM Retrieval on Property Crime and Behaviour.

\begin{tabular}{|l|c|c|c|c|c|}
\hline Sex & Increase in phone snatching & Increase in the theft of valuable & Insincere attitude & Non-challent attitude & Total \\
\hline Male & $53(52.4 \%)$ & $57(40.7 \%)$ & $43(49.4 \%)$ & $30(50.8 \%)$ & 183 \\
\hline Female & $48(47.5 \%)$ & $83(59.3 \%)$ & $44(50.6 \%)$ & $29(49.2 \%)$ & 204 \\
\hline Total & $101(100)$ & $140(100)$ & $87(100)$ & $59(100)$ & 387 \\
\hline
\end{tabular}

Source: Fieldwork, 2013.

These findings are in consonance with the observation of Michael et al (2013) that there is an upsurge in criminal activities especially property crime. The unfavourable socio-economic condition has continued to trigger astronomical increase in property crime in Nigeria. Even with the proliferation of mobile phones and the drastic reduction in their prices, criminals still steal GSM handset from subscribers on daily basis. The table depicted that there is high level of insincerity among members of the society. As shown on table 5,50.6\% and $49.4 \%$ of the female and male participants respectively perceived that the prevalence of SIM retrieval shows insincerity among members of the society as most subscribers who opted for SIM retrieval may have loss their phones with SIM in public places such as hospitals, school, offices and vehicles without getting them back. When such phones are picked up and not returned to the owners or the nearest Police Station, it shows insincerity on the part of those who picked up the phones. According to Adeoti (2008) insincerity manifest in being in possession of property that is not yours and not ever willing to return same to the owner or relatives, even you have various avenues to return same. This finding corroborates the earlier stance of Akpan (2010) that many Nigerians are insincere as they pick up objects and materials belonging to another person without returning them to the owners. Finally, the table showed that about $51 \%$ percent of the male respondents and $49 \%$ of their female counterparts respectively perceived that the prevalence of SIM retrieval implies that many subscribers are carefree. They do not take proper care of their properties even in public places.

\section{Conclusion and Recommendation}

The study examined subscriber SIM cards retrieval in Calabar Municipality. It was established from this study that the prevalence in SIM card retrieval is attributed to the increased in the number of stolen handsets containing SIMs, brought about by myriad of socio-economic problems in our society and loss of phones, damage and faulty SIM cards of subscribers. Subscribers prefer retrieving their previous SIMs so as to prevent criminals from using their lines for crime, to enable them reconnect with their associates, friends and loved ones. The study established that more females than males are more likely to have their SIM cards retrieved, because there are common victims of stolen phones with SIMs, lose more phones with SIMs than male and can easily have their SIMs damaged by their husbands, boyfriends and fiancés because of the patriarchal nature of Nigerian society where men exert control over the women. The prevalence of SIM retrieval implies that crime against property such as snatching of phones, theft of valuables is on the increase and that there is high level of insincerity among members of the society as lost phones are not returned to owners. The rate at which subscribers lose their phones in public places such as schools, hospitals and markets, implies that a lot of them have carefree attitude towards handling their belongings.

We therefore recommend that government should ensure that the problem of unemployment is addressed since unemployment is fingered as one of the triggers of property crime in Nigeria. The government through the National Orientation Agency (NAO) should ensure that there is need for value reorientation in Nigeria. This will invariably inculcate on members of the society moral values which many Nigerians are bankrupt and that the Nigerian Communication Commission should mandate network providers to ensure that durable SIM cards are produced. Finally, the processes involved in SIM retrieval by various network providers should be simplified so that subscribers will not have to spend several hours and days before retrieving their lost or stolen SIM cards. 


\section{References}

Adaramola,Z .(2013).NCC must keep telecoms operatives on their toes. Daily Trust. May 15, 12-14

Adeoti, P.S (2008). School, morality and society. PortHarcourt: Davdstone Publishers.

Adeyinka, T; Ajiboye, J.O; Emmanuel A.O and Wojuade, J.I. (2007). Stakeholders' perception of the impact of global system for mobile communication on Nigeria rural economy: implications for an emerging communication industry. The Journal of community informatics, 3 (4) 78-79

Agba, A.M O; Ikoh, M U, Ushie, E .M and Bassey, A. O. (2010). Telecommunications revolution: implication on criminality and family crises in the South-South states of Nigeria. Computer and information science. 3 (1) $42-50$

Ajanaku,L(2013).NCC directs MTN to raise tarrif. The Nation. April 30, 2013,pp 9-10

Ajanaku,L.(2013).GLO.ZTE Sign \$500m upgrade agreement. The Nation. April 30 ,2013,pp 9-10.

Akpan, P. (2010) Socio-economic impact of global system for mobile telecommunication in Okobo Local Government Area. Unpublished B.SC Project, Department of Sociology, university of calabar.

Amadi, P.S (2010). Technology and crime in developing countries. Nsukka: Ikenna Publishers.

Bakare, A.S and Gold,K.I (2011). Estimating the impact of global system for mobile telecommunication (GSM) on income. Journal of economics and international finance. 3(3) 37-45

Bogare,H.(2011).Mobile phone owners to register SIM cards. Retrieved from:http://www.observer.ug/index.php.

Hitimana,B.(2011). EA regulators push for SIM registration to curb crime. Retrieved from http:// www.busiweek.com/news/rwanda/1122ea=regulators-push-for-sim-registration-to-curb-crim.

Kenneth, O.N.(2007). The impact of GSM mobile phones on Nigerians. Retrieved from http://www. Ezinearticles.com

Longe, O.M and Oguntuyi. V.F (2012). Global system for mobile communication :Its praises and pains in Nigeria. Journal of communication and computer. 9(20102) 1293-1297.

Latour,B. (1997).On actor network theory: A few clarifications. Retrieved from http://enwkipedia.org/wiki/actor networktheory.

Michael,C.E.(2010).Public perception of the involvement of commercial motorcyclists in crime in Uyo Metropolis.Unpublished M.Sc thesis,Department of Sociology, University of Ibadan,Ibadan.

Michael, C.E. Ojedoku, U A and Chinwokwu, E.C (2013). Abolition of commercial motorbikes and its implication on transportation and criminality. International Journal of social science studies (1), 206-214.

Ndukwe, E. (2005). Three years of GSM revolution in Nigeria. Retrieved from http/lwww.ncc.gov.ng/speeches-presentation/Evc's.

Nigeria Communication Commission (NCC) industry statistics-subscriber data at a glance. Retrieved from http/lwww.ncc.ng

Nurudeem,N.J.(2013).Telecom: soaring investment ,bad network. The Daily Trust. May 15,21-22

Nwadike, O.S (2010). An evaluation of the impact of global system for mobile telecommunication (GSM) on household income in Ihiala Local Government Area. Unpublished B.SC project, University of Uyo.

Olubamidele, O.F (2012). Public perception of the impact of GSM: A study in selected LGA in Lagos State. Unpublished B.SC project. Department of sociology, Nasarawa State University.

Rischard,J.F.(1996).Connecting developing countries to the information technology revolution. Project Muse 16 (1) 93-107

Smith, G.N. (2009).Introduction to information and communication technology. Calabar: Clear Lines publications.

Ukwayi, J.K; Agba,A.M.O, Michael,C.E. (2013).Public Perception of the involvement of commercial motorcyclists in crime in SouthSouth, Nigeria. International Journal of Humanities and Social Science Invention. 2(7)21-31. 